\title{
Stereotactic radiotherapy of pancreatic cancer: a systematic review on pain relief
}

This article was published in the following Dove Press journal: Journal of Pain Research

\author{
Milly Buwenge' \\ Gabriella Macchia ${ }^{2}$ \\ Alessandra Arcelli' \\ Rezarta Frakulli ${ }^{3}$ \\ Lorenzo Fuccio 4 \\ Sara Guerri' \\ Elisa Grassi' \\ Silvia Cammelli' \\ Francesco Cellini ${ }^{5}$ \\ Alessio G Morganti' \\ 'Department of Experimental, \\ Diagnostic and Specialty Medicine \\ - DIMES, University of Bologna, S. \\ Orsola-Malpighi Hospital, Bologna, \\ Italy; ${ }^{2}$ Radiation Oncology Unit, \\ Research and Care Foundation \\ "Giovanni Paolo II", Catholic \\ University of Sacred Heart, \\ Campobasso, Italy; ${ }^{3}$ Radiation \\ Oncology Unit, Bellaria Hospital, \\ Bologna, Italy; ${ }^{4}$ Department of Medical \\ and Surgical Sciences - DIMEC, \\ University of Bologna, S. Orsola- \\ Malpighi Hospital, Bologna, Italy; \\ ${ }^{5}$ Department of Radiotherapy, "A. \\ Gemelli” Hospital, Catholic University, \\ Rome, Italy
}

Correspondence: Alessandra Arcelli Radiation Oncology Center, Department of Experimental, Diagnostic and SpecialtyMedicine - DIMES, University of Bologna, S. Orsola-Malpighi Hospital, via Giuseppe Massarenti 9, Bologna 40I38, Italy

Tel +3905I 6363564

Fax +3905I 6364336

Email rt.unibo@gmail.com

\begin{abstract}
Locally advanced pancreatic carcinoma (LAPC) has a poor prognosis and the purpose of treatment is survival prolongation and symptom palliation. Radiotherapy has been reported to reduce pain in LAPC. Stereotactic RT (SBRT) is considered as an emerging radiotherapy technique able to achieve high local control rates with acceptable toxicity. However, its role in pain palliation is not clear. To review the impact on pain relief with SBRT in LAPC patients, a literature search was performed on PubMed, Scopus, and Embase (January 2000-December 2017) for prospective and retrospective articles published in English. Fourteen studies (479 patients) reporting the effect of SBRT on pain relief were finally included in this analysis. SBRT was delivered with both standard and/or robotic linear accelerators. The median prescribed SBRT doses ranged from 16.5 to $45 \mathrm{~Gy}$ (median: $27.8 \mathrm{~Gy}$ ), and the number of fractions ranged from 1 to 6 (median: 3.5 ). Twelve of the 14 studies reported the percentage of pain relief (in patients with pain at presentation) with a global overall response rate (complete and partial response) of $84.9 \%$ (95\% CI, 75.8\%-91.5\%), with high heterogeneity $\left(Q^{2}\right.$ test: $\left.P<0.001 ; I^{2}=83.63 \%\right)$. All studies reported toxicity data. Acute and late toxicity (grade $\geq 3$ ) rates were $3.3 \%-18.0 \%$ and $6.0 \%-8.2 \%$, respectively. Reported gastrointestinal side effects were duodenal obstruction/ ulcer, small bowel obstruction, duodenal bleeding, hemorrhage, and gastric perforation. SBRT achieves pain relief in most patients with pancreatic cancer with an acceptable gastrointestinal toxicity rate. Further prospective studies are needed to define optimal dose/fractionation and the best systemic therapies modality integration to reduce toxicity and improve the palliative outcome. Finally, the quality of life and, particularly, pain control should be considered as an endpoint in all future trials on this emerging treatment technique.
\end{abstract}

Keywords: radiotherapy, pancreatic neoplasms, systematic review, palliative, pain

\section{Introduction}

Locally advanced pancreatic carcinoma (LAPC) is a lethal disease associated with multiple debilitating symptoms and $38.7 \%-49.1 \%$ rates of 1 -year survival. ${ }^{1}$ Moreover, quality of life (QoL) is poor because of several symptoms such as jaundice, weight loss, obstruction, and, particularly, pain. The latter is very frequent because of pancreatic tissue innervation by networks interacting with both the sympathetic and parasympathetic systems yielding to increased sensitivity. Therefore, pain relief is a major goal of palliative treatment in patients with LAPC. ${ }^{2}$

Radiotherapy (RT) has been used as a noninvasive treatment in the management of these patients to achieve local control and pain relief. Particularly, prolonged (5-6 weeks) concurrent chemoradiation has been considered as a treatment option in LAPC. However, this combined modality treatment may produce discomfort in these patients 
with poor performance status due to treatment duration and not negligible toxicity.

Stereotactic RT (SBRT) is an emerging treatment technique for LAPC patients due to several factors such as the possibility to deliver high biological doses to the tumor because of the lower irradiation of organs at risk. ${ }^{3}$ Furthermore, due to the short treatment duration, SBRT produces less discomfort to the patients and can be easily combined with standard chemotherapy. Based on the reported efficacy in terms of local control, SBRT has the theoretical potential to relieve pain in LAPC patients. However, this issue has never been systematically analyzed in prospective studies or meta-analyses.

Therefore, the aim of this study is to systematically review the available evidences on pain control after SBRT in patients with LAPC.

\section{Materials and methods}

A systematic search in the electronic databases of PubMed, Embase, and Scopus (January 2000-December 2017) for full-text published studies on SBRT in pancreatic cancer (PC) was performed. Only studies published in English were included in this review. Prospective and retrospective studies on LAPC treated with SBRT and reporting on pain control were included in the review. Case reports, review articles, and published conference abstracts were excluded. The following search strategy was used in PubMed database: ("pancreatic neoplasms" [MeSH Terms]) OR ("pancreatic" [All Fields] AND “neoplasms" [All Fields]) OR "pancreatic neoplasms" [All Fields] OR ("pancreatic" [All Fields] AND "cancer" [All Fields]) OR ("pancreatic cancer" [All Fields]) AND ("radiotherapy" [Subheading] OR "radiotherapy" [All Fields] OR "radiotherapy" [MeSH Terms]) AND ("pain" [MeSH Terms] OR “pain” [All Fields]).

Two independent authors (MB, GM) screened citations at the title and abstract level to identify potentially relevant studies without any duplication. Potentially eligible citations were retrieved for full-text review and any uncertainty was resolved by another author (AGM). The following information was extracted from each study: year of publication, study design, inclusion criteria, total number of patients and number of patients with pain, stage, irradiation technique, planning target volume (PTV) definition, dose prescription, median RT dose, median biologically equivalent doses in 2 Gy fractions (EQD $; \alpha / \beta: 3$ and 10$)$, percentage of patients receiving chemotherapy, pain response rate and evaluation criteria, pain-free survival, and toxicity. The median $\mathrm{EQD}_{2}$ was calculated from the prescribed tumor doses by using an $\alpha / \beta$ value of $3 \mathrm{~Gy}$ for late effects and $10 \mathrm{~Gy}$ for tumor effects.

\section{Outcome measures}

The main outcome measure was pain relief evaluated by reduction of analgesic administration, suspension of analgesic administration, and partial response (PR) and complete response (CR). Secondary outcome measures were toxicity and pain-free survival.

\section{Statistical analysis}

Proportions and rates were pooled by means of a randomeffects model in case of heterogeneity across studies; otherwise, a fixed-effect model was used. The dependent variables were modeled on the logit (log-odds) scale, converted back to percentages, and then presented as point estimates and 95\% CI. Statistical heterogeneity was quantified with the $I^{2}$ statistic (high heterogeneity level: $>50 \%$ ) and tested using the $Q^{2}$ test (statistical significance level: $P<0.1)$. All tests were two-sided, and statistical significance was taken as $P<0.05$, except when investigating heterogeneity across studies, in which case it was taken as $P<0.10$. All the analyses were performed using the MEDCALC statistical software.

\section{Results \\ Search results}

From a total of 231 retrieved publications, after applying the selection criteria, 14 studies were found suitable for the analysis (Figure 1). ${ }^{4-17}$

The design of the analyzed papers was prospective in seven studies and retrospective in the other seven studies. According to the extracted data, different scenarios of advanced disease were included (LAPC with or without metastatic disease and locally recurrent PC both after surgery and/or RT). From a total of 469 patients, 190 patients reported with pain before SBRT treatment in 12 studies. ${ }^{4-7,9-12,14-17}$ Two studies ${ }^{8,13}$ did not report the number of patients with pain before SBRT.

\section{Literature review}

Hoyer et al treated 22 patients using a standard linear accelerator (LINAC) and delivering $45 \mathrm{~Gy}$ in three fractions $\left(\mathrm{EDQ}_{2}: 93.8 \mathrm{~Gy}\right)$ to a PTV defined as the gross tumor volume (GTV) plus edema plus 5-10 mm margin. Chemotherapy was not used, and no pain response was recorded. The authors reported increased pain 2 weeks after treatment and 22.5\% of patients experiencing severe gastrointestinal (GI) toxicity. ${ }^{4}$ 


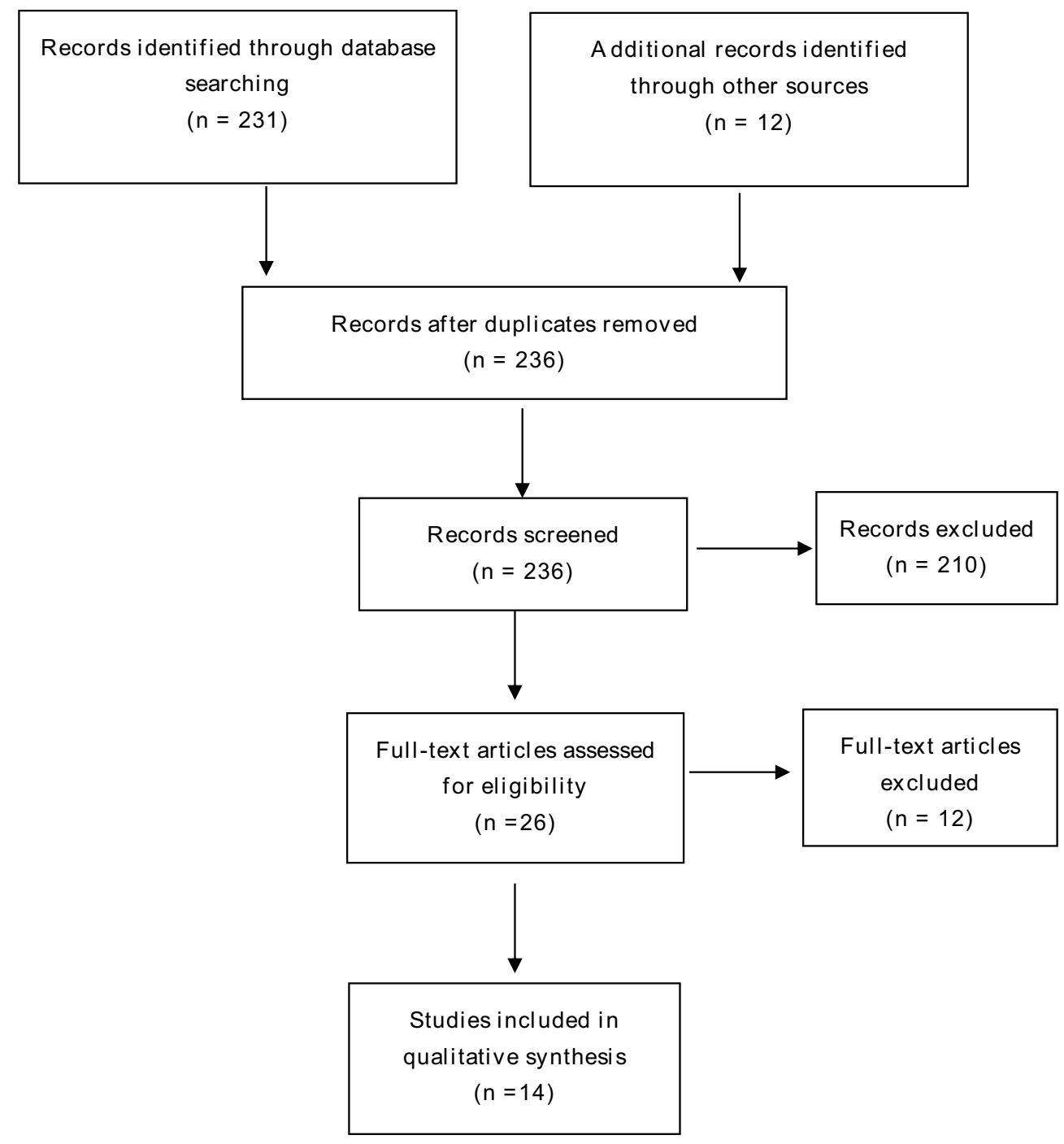

Figure I Flow diagram of study identification and selection.

Seo et al treated 30 patients with T4 stage (N1:30\%) in a Phase I dose escalation study using a robotic LINAC. A single SBRT fraction dose between 14 and $17 \mathrm{~Gy}$ (median: 16.5 Gy; $\mathrm{EDQ}_{2}: 76.4 \mathrm{~Gy}$ ) was delivered to the PTV (GTV $+2-4 \mathrm{~mm}$ ) as a boost after conformal RT. Seventy percent of patients received induction or adjuvant chemotherapy and $55.6 \%$ of patients reported reduced analgesic consumption (RAA). ${ }^{5}$

Didolkar et al treated 85 LAPC patients ( $24.5 \%$ of them also had distant metastases) using a robotic device to deliver a dose between 15 and 30 Gy (median: $25.5 \mathrm{~Gy}$ ) in three fractions (median $\left.\mathrm{EDQ}_{2}: 39.3 \mathrm{~Gy}\right)$ to the PTV (GTV +3 $\mathrm{mm}$ ). Chemotherapy was administered to $100 \%$ of patients after SBRT. The authors reported $48.4 \% \mathrm{CR}$ and $51.6 \% \mathrm{PR}$ using a $0-10$ scale, $18-24$ weeks pain-free survival, and late toxicity (hemorrhage/obstruction) in $8.2 \%$ patients. $^{6}$
Shen et al treated 20 LAPC patients using a robotic LINAC to deliver 32-55 Gy (median: 45 Gy; EDQ $2: 79.7$ Gy) in three to six fractions (median: 4) to the PTV (GTV $+3-5 \mathrm{~mm}$ ). Chemotherapy was not administered. The authors reported $90 \%$ pain relief using a visual analog scale (VAS). ${ }^{?}$

Polistina et al treated 23 patients with LAPC and $<6 \mathrm{~cm}$ maximum tumor size using a robotic device to deliver 30 Gy in three fractions $\left(\mathrm{EDQ}_{2}: 50.0 \mathrm{~Gy}\right)$. Both induction and adjuvant chemotherapy were administered in all patients before and after SBRT. The authors did not report significant reduction in pain response using a VAS scale. ${ }^{8}$

Rwigema et al treated 71 patients (LAPC: 56 ; recurrence: 16; metastatic disease: 11 ; residual disease after surgery: 17) using a standard or robotic LINAC to deliver a single fraction of 18-25 Gy (median: 24; $\mathrm{EDQ}_{2}: 68.0 \mathrm{~Gy}$ ) to the PTV (GTV $+2 \mathrm{~mm})$. Ninety percent of patients received 
both induction and adjuvant chemotherapy. The authors reported $81.3 \% \mathrm{CR}^{9}$

Macchia et al treated 16 PC patients (cT4: 87.5\%, local recurrence: $12.5 \%$ ) using a standard LINAC to deliver 20-35 Gy (median: $25 \mathrm{~Gy} ; \mathrm{EDQ}_{2}: 31.3 \mathrm{~Gy}$ ) in five fractions prescribed to the PTV (GTV $+\geq 10 \mathrm{~mm}$ ). All patients received chemotherapy before SBRT. The authors reported CR, PR, and RAA as $25.0 \%, 31.3 \%$, and $40.0 \%$, respectively. Late toxicity (duodenal bleeding) was recorded in $6.2 \%$ of patients. ${ }^{10}$

Wild et al treated 18 patients with LAPC or recurrent disease using a standard LINAC to deliver 20-27 Gy (median: $25 \mathrm{~Gy} ; \mathrm{EDQ}_{2}: 31.3 \mathrm{~Gy}$ ) in five fractions to the PTV (internal target volume $+1-3 \mathrm{~mm}$ ). Chemotherapy was administered to $28.0 \%$ of patients after SBRT. The authors reported $57.0 \%$ "effective palliation" and $6.0 \%$ late small bowel obstruction. ${ }^{11}$

Tozzi et al treated 30 patients with LAPC or recurrent disease using a standard LINAC to deliver 45 Gy in six fractions $\left(\mathrm{EDQ}_{2}: 65.5 \mathrm{~Gy}\right)$ to the PTV $(\mathrm{GTV}+5-10 \mathrm{~mm})$. Chemotherapy was administered before SBRT to all patients. The authors reported suspension of analgesic administration (SAA) and RAA in $63.6 \%$ and $36.4 \%$ of patients, respectively, using a Numerical Rating Scale (NRS). ${ }^{12}$

Herman et al treated 49 LAPC patients using a standard LINAC to deliver $33 \mathrm{~Gy}$ in five fractions $\left(\mathrm{EDQ}_{2}: 45.7 \mathrm{~Gy}\right)$ to the PTV (GTV $+2-3 \mathrm{~mm}$ ). Induction chemotherapy was administered to $90.0 \%$ of patients and adjuvant chemotherapy to all patients after SBRT. The authors reported a reduction of 8 points of pain from baseline ( 25 points) using the quality of life questionnaire for patients with pancreatic cancer (QLQPAN 26) scoring system. GI late toxicity rate was $6.4 \% .^{13}$

$\mathrm{Su}$ et al treated 25 patients with LAPC or metastatic disease using a robotic LINAC to deliver 36 Gy in three fractions $\left(\mathrm{EDQ}_{2}: 66.0 \mathrm{~Gy}\right)$ or $30-48 \mathrm{~Gy}$ in three to four fractions to the PTV (GTV $+1-2 \mathrm{~mm})$. Both induction and adjuvant chemotherapy were used in $8.0 \%$ of patients before and after SBRT. The authors reported $50.0 \%$ and $15.0 \%$ SAA and RAA rates, respectively, using an NRS scale. ${ }^{14}$

Kim et al treated 26 not operable patients using a standard or robotic LINAC to deliver a median dose of 24 Gy (range: 24-36 Gy) in one to three fractions (median $\mathrm{EDQ}_{2}$ : $68.0 \mathrm{~Gy})$ to the PTV (GTV $+2 \mathrm{~mm}$ ). Induction and adjuvant chemotherapy were used in $15.0 \%$ and $23.0 \%$ of patients, respectively. The authors reported SAA in $35.7 \%$ of patients. ${ }^{15}$

Comito et al treated 31 patients with isolated recurrent disease using a Flattening Filter Free Rapidarc technique to deliver 45 Gy in six fractions $\left(\mathrm{EDQ}_{2}: 65.5 \mathrm{~Gy}\right)$ to the PTV $(\mathrm{GTV}+5-7$ $\mathrm{mm})$. Induction and adjuvant chemotherapy was administered in $20.0 \%$ and $77.0 \%$ of patients before and after SBRT, respec- tively. The authors reported SAA and RAA in 58.0\% and 40.0\% of patients, respectively, using an NRS scale. ${ }^{16}$

Koong et al treated 23 previously irradiated patients with local recurrences using a standard or robotic LINAC to deliver 25 Gy in five fractions $\left(\mathrm{EDQ}_{2}: 31.3 \mathrm{~Gy}\right)$ to the PTV (internal target volume $+2-3 \mathrm{~mm}$ ). Induction chemotherapy was delivered in $26.1 \%$ of patients. The authors reported "pain improvement" in $57.1 \%$ of patients. ${ }^{17}$

Patients' clinical stage was not reported in nine studies. ${ }^{6,8,11-14,16,17}$ In one study, $100 \%$ of patients had cT4 tumor stage, ${ }^{5}$ while in another trial, this rate was $87.5 \% .{ }^{10}$ In two studies only, patients with stage II-IV were enrolled ${ }^{7,15}$ and in another, all patients had T1-3 N0 M0 PC. ${ }^{4}$

Different treatment devices were used including robotic LINACs (six reports), ${ }^{5-8,14,16}$ standard LINACs (five studies), ${ }^{4,10-13}$ and both (three papers). ${ }^{9,15,17}$

Thirteen studies reported the details of PTV definition: eleven studies used a 1-5 mm GTV/internal tumor volume to PTV margin, ${ }^{5-7,9,11-17}$ one study used a $>10 \mathrm{~mm}$ GTV to PTV margin, ${ }^{10}$ and only Hoyer et al defined the PTV as the GTV plus edema plus 5-10 $\mathrm{mm}^{4}$

Dose prescription, reported in 12 of 14 papers, was according to the International Commission on Radiation Units-62 in one study ${ }^{10}$ and to specific isodose lines ranging from $67 \%$ to $100 \%$ in eleven studies..$^{4-7,9,11-16}$ The median prescribed SBRT doses ranged from 16.5 to 45 Gy (median: $27.8 \mathrm{~Gy}$ ), while the number of fractions ranged from 1 to 6 (median: 3.5 ). The computed median $\mathrm{EQD}_{2[\alpha / \beta=10]}$ ranged from 31.3 to $93.8 \mathrm{~Gy}$ (median: $65.5 \mathrm{~Gy}$ ) and the median $\mathrm{EQD}_{2[\alpha /}$ $\beta=3$ ] from 40.0 to $162.0 \mathrm{~Gy}$ (median: $95.0 \mathrm{~Gy}$ ).

Twelve studies reported induction or adjuvant chemotherapy regimens in patients ranging from $8.0 \%$ to $100.0 \%{ }^{5,6,8-17}$ The characteristics and main results of these publications are reported in Table 1.

\section{Pain relief}

The pain response was scored using different scales: NRS in three studies, ${ }^{12,14,16}$ VAS in three studies, ${ }^{6-8}$ and QLQ-PAN-26 in one study. ${ }^{13}$ Six studies did not report the assessment scale. ${ }^{4,5,10,11,15,17}$ Twelve of the 14 studies reported various rates of pain relief. ${ }^{5-7,9-17} \mathrm{Six}$ studies ${ }^{5,10,12,14-16}$ reported $69.50 \%$ rates of RAA or SAA (95\% CI, 59.49\%-78.31\%), with high heterogeneity between studies ( $Q^{2}$ test: $\left.P<0.0001 ; I^{2}=86.44 \%\right)$ to describe pain relief after SBRT (Figure 2). Three studies reported $54.25 \% \mathrm{CR}$ rates in 56 patients $(95 \% \mathrm{CI}$, $40.76 \%-67.29 \%)$, with high heterogeneity $\left(Q^{2}\right.$ test: $P<0.013$; $\left.I^{2}=76.68 \%\right)^{9,5,8}$ (Figure 3 ). Overall global response rate to pain in terms of CR or PR as reported in 85 patients from 
five studies was $84.9 \%$ (95\% CI, 75.8\%-91.5\%), with high heterogeneity again $\left(Q^{2}\right.$ test: $\left.P<0.001 ; I^{2}=83.63 \%\right),{ }^{5,6,8,9,14,16}$ as shown in Figure 4. Only one study ${ }^{6}$ reported pain-free survival ranging from 18 to 24 weeks. One study reported no significant pain reduction, ${ }^{8}$ while another study reported a significant worsening of pain 2 weeks after SBRT. ${ }^{4}$

\section{Toxicity}

All studies reported toxicity using the following scoring systems: Radiation Therapy Oncology Group in four studies, ${ }^{5,7,10,15}$ CTCAE in five studies, ${ }^{6,8,12,16,17}$ and WHO in one study, ${ }^{4}$ while four studies did not report the used scale. ${ }^{9,11,13,14}$ Acute and late toxicity (grade $\geq 3$ ) rates were 3.3\%-18.0\% and $6.0 \%-8.2 \%$, respectively. Reported gastrointestinal complications were duodenal obstruction/ulcer, small bowel obstruction, duodenal bleeding, hemorrhage, and gastric perforation.

\section{Discussion}

We performed a systematic review to analyze the impact of SBRT on pain control in patients with PC. Our analysis has several limitations. Overall, only few studies that reported on pain control were included in the analysis. Secondly, only 4/14 studies had a prospective design, and are therefore more credible in the evaluation of results. Furthermore, in eleven studies, the number of patients with pain before treatment was $<20$. Inclusion criteria were inconsistent, with some studies including only primary tumors and others also including local recurrences. Treatment techniques were uneven in terms of target definition, dose and fractionation, and dose prescription. In addition, percentages of patients who underwent chemotherapy were variable between the different studies. Finally, criteria and methods for assessing pain and toxicity were widely variable in the analyzed papers.

Another limitation of our study is the lack of a systematic evaluation of the quality of the analyzed studies and, in particular, the risk of bias. However, having clearly observed that no study considered pain palliation as a primary objective and that the description of this endpoint was reported in all the studies in a synthetic and not systematic way, it is obvious that for the purposes of our analysis, all the studies have a low-level quality.

However, despite these limitations, most studies reported pain improvement after SBRT. Only two studies reported no changes ${ }^{8}$ or pain worsening. ${ }^{4}$ Nevertheless, it should be noted that in the first study, the comparison between VAS before and after SBRT was performed in all treated patients, without any separate analysis on the group with pain before treatment. ${ }^{8}$ Obviously, this limitation could have reduced the possibility to detect a significant improvement of pain. The second study was the one delivering the highest $\mathrm{EQD}_{2}$ (using $\alpha / \beta$ values of 3 and 10) from all the analyzed series. ${ }^{4}$ Furthermore, the PTV was defined with larger margins compared to those reported in all other studies (GTV+surrounding edema+5-10 $\mathrm{mm}$ ). This is probably the reason of the high GI complications rate (grade $\geq 3: 22.5 \%$ ) and of increased pain due to gastricduodenal ulcerations. ${ }^{4}$

Except for these two studies, in all other reports, a reduction in pain was achieved, in most cases exceeding $50 \%$ of patients. The variability of symptomatic response evaluation hinders the analysis of dose and pain response relationship. However, it could be noted that considering the studies reporting the pain $\mathrm{CR}$ rate, this value was $<50 \%$ in two studies with 31.3 and 39.3 Gy median $\mathrm{EDQ}_{2[\alpha / \beta=10]}{ }^{6,10}$ and was $81.3 \%$ in a study with 68.0 Gy median $\mathrm{EDQ}_{2[\alpha / \beta=10]}{ }^{9}$

In some studies, cases of severe GI toxicity were recorded. The prevention of toxicity should be pursued to avoid worsening of QoL in these patients with generally poor performance status. ${ }^{18,19}$

Trying to correlate the $\mathrm{EQD}_{2[\alpha / \beta=3]}$ with late toxicity, no clear threshold between delivered dose and long-term side effects was observed. In fact, in some series with low (40 Gy) $\mathrm{EQD}_{2[\alpha / \beta=3]}$, both late bleeding ${ }^{10}$ and bowel obstruction ${ }^{11}$ were reported, while in most series with high (104.4-129.6 Gy) $\mathrm{EQD}_{2[\alpha / \beta=3]}$, no cases of late toxicity were observed. $5,7,9,14,15$

More specifically, in the studies reporting cases of late toxicity, ${ }^{4,6,10,11,13}$ the median $\mathrm{EQD}_{2}(\alpha / \beta$ : 3) was $58.6 \mathrm{~Gy}$ (range: 40.0-162.0 Gy), while in the studies not reporting late toxicity, ${ }^{5,7-9,12,14-17}$ the median value was 104.4 Gy (range: $40.0-135.0 \mathrm{~Gy})$. On the basis of these paradoxical data, it is difficult to identify a correlation between dose and toxicity. If we consider the series in which $>50 \%$ of patients received chemotherapy, ${ }^{5,6,8-10,12,13,16}$ three out of eight studies reported late toxicity (37.5\%). Instead, if we consider studies in which $<50 \%$ of patients received chemotherapy, ${ }^{11,14,15,17}$ only onefourth reported late toxicity (25\%). This is evidently a modest difference that does not allow us to establish a clear correlation between chemotherapy and radiation-induced toxicity. Instead, considering the studies reporting the maximum GTV to PTV radial margin, we observed that the median value was $6.5 \mathrm{~mm}$ (range: $3-10 \mathrm{~mm}$ ) in the studies with late toxicity $4,6,10,13$ and $2 \mathrm{~mm}$ (range: $2-7 \mathrm{~mm}$ ) in the studies without late toxicity. ${ }^{5,7,9,12,14-16}$ From this simple qualitative assessment, the width of the GTV-PTV margins seems to be the parameter most correlated to toxicity.

The results of our study in terms of the relationship between toxicity and dose are different compared to those of 
Table I Characteristics and outcomes of analyzed studies

\begin{tabular}{|c|c|c|c|c|c|c|c|}
\hline $\begin{array}{l}\text { Author, } \\
\text { year }\end{array}$ & Study design & $\begin{array}{l}\text { Inclusion } \\
\text { criteria }\end{array}$ & $\begin{array}{l}\text { Patients } \\
\text { (with } \\
\text { pain) }\end{array}$ & Stage & Technique & PTV & $\begin{array}{l}\text { Dose } \\
\text { prescription }\end{array}$ \\
\hline $\begin{array}{l}\text { Hoyer et al, } \\
2005^{4}\end{array}$ & Phase I-II & LA & $\begin{array}{l}22 \\
(15)\end{array}$ & $\begin{array}{l}\mathrm{T}_{1-} \\
{ }_{3} \mathrm{~N}_{0} \mathrm{M}_{0}\end{array}$ & $\begin{array}{l}\text { SBRT with } \\
\text { standard LINAC }\end{array}$ & $\begin{array}{l}\text { GTV+edema+5-10 } \\
\mathrm{mm}\end{array}$ & $\begin{array}{l}\text { PTV } \\
\text { encompassed } \\
\text { by } 67 \% \\
\text { isodose }\end{array}$ \\
\hline $\begin{array}{l}\text { Seo et al, } \\
2009^{5}\end{array}$ & Phase I & $\begin{array}{l}\text { LA, no } \\
\text { duodenal } \\
\text { invasion, } \\
<3 \mathrm{~N}+\end{array}$ & $\begin{array}{l}30 \\
(18)\end{array}$ & $\begin{array}{l}\mathrm{T}_{4}: \\
100.0 \% \\
\mathrm{~N}_{1}: \\
30.0 \%\end{array}$ & RRS & $\begin{array}{l}\mathrm{GTV}+2 \mathrm{~mm} \\
(4 \mathrm{~mm} \mathrm{CC})\end{array}$ & $\begin{array}{l}\text { To isodose } \\
\text { covering } 97 \% \\
\text { of PTV }\end{array}$ \\
\hline $\begin{array}{l}\text { Didolkar } \\
\text { et al } 2010^{6}\end{array}$ & Retrospective & LA & $\begin{array}{l}85 \\
\text { (Moderate: } \\
21.2 \% \text {, } \\
\text { severe: } \\
15.3 \% \text { ) }\end{array}$ & $\begin{array}{l}\text { LA } \\
M_{1}: \\
24.7^{c}\end{array}$ & RSBRT & $\mathrm{GTV}+3 \mathrm{~mm}$ & $\begin{array}{l}\text { To } 80 \% \\
\text { isodose }\end{array}$ \\
\hline $\begin{array}{l}\text { Shen et al, } \\
2010^{7}\end{array}$ & Case series & LA & $\begin{array}{l}20 \\
(15)\end{array}$ & $\begin{array}{l}\text { Stage } \\
\text { II-III }\end{array}$ & RSBRT & $\mathrm{GTV}+3-5 \mathrm{~mm}$ & $V_{75 \%}>95 \%$ \\
\hline $\begin{array}{l}\text { Polistina } \\
\text { et al, } 2010^{8}\end{array}$ & Case series & $\mathrm{LA}<6 \mathrm{~cm}$ & $\begin{array}{l}23 \\
(\mathrm{NR})\end{array}$ & $\begin{array}{l}\mathrm{N}_{1}: \\
60.8 \%\end{array}$ & RSBRT & NR & NR \\
\hline $\begin{array}{l}\text { Rwigema } \\
\text { et al, 201 }{ }^{9}\end{array}$ & Retrospective & LA or $M I^{e}$ & $\begin{array}{l}71 \\
(16)\end{array}$ & $\begin{array}{l}\text { LA: } 56 \\
\text { Rec: } 16 \\
M_{1}: 11 \\
R_{1}: 17\end{array}$ & RRS or LINAC & $\mathrm{GTV}+2 \mathrm{~mm}$ & $\begin{array}{l}\text { To } 80 \%-89 \% \\
\text { isodose }\end{array}$ \\
\hline $\begin{array}{l}\text { Macchia } \\
\text { et al, } 2012^{10}\end{array}$ & Phase I & LA & $\begin{array}{l}16 \\
(9)\end{array}$ & $\begin{array}{l}T_{4}: \\
87.5 \%{ }^{f} \\
\text { Rec: } \\
12.5 \% \text { f }\end{array}$ & $\begin{array}{l}\text { SBRT with } \\
\text { standard LINAC }\end{array}$ & $\mathrm{GTV}+\geq 10 \mathrm{~mm}$ & ICRU-62 \\
\hline $\begin{array}{l}\text { Wild et al, } \\
2013^{11}\end{array}$ & Retrospective & $\begin{array}{l}\text { LA or } \operatorname{Rec} \\
\text { (previous } \\
\text { RT) }\end{array}$ & $\begin{array}{l}18 \\
(7)\end{array}$ & $\begin{array}{l}\text { LA: } \\
\text { 16.7\% } \\
\text { Rec: } \\
83.3 \%\end{array}$ & SBRT & $\mathrm{ITV}+\mathrm{I}-3 \mathrm{~mm}$ & $\begin{array}{l}\text { To isodose } \\
\text { surrounding } \\
\text { PTV }\end{array}$ \\
\hline $\begin{array}{l}\text { Tozzi et al, } \\
2013^{12}\end{array}$ & Case series & $\begin{array}{l}\text { LA or Rec } \\
\leq 5 \mathrm{~cm}\end{array}$ & $\begin{array}{l}30 \\
(11)\end{array}$ & $\begin{array}{l}\text { LA: } 70 \% \\
\text { Rec: } \\
30 \%\end{array}$ & VMAT FFF & $\begin{array}{l}\mathrm{GTV}+5 \mathrm{~mm}(10 \\
\mathrm{mm} \mathrm{CC})\end{array}$ & $\begin{array}{l}\text { CTV } \\
V_{95 \%}=100 \%\end{array}$ \\
\hline $\begin{array}{l}\text { Herman } \\
\text { et al, } 2015^{13}\end{array}$ & Phase II & LA & $\begin{array}{l}49 \\
(\mathrm{NR})\end{array}$ & NR & SBRT (VMAT) & $\mathrm{GTV}+2-3 \mathrm{~mm}$ & $V_{100 \%}>90 \%$ \\
\hline $\begin{array}{l}\text { Su et al, } \\
2015^{14}\end{array}$ & Retrospective & LA or MI & $\begin{array}{l}25 \\
(20)\end{array}$ & $\begin{array}{l}\text { LA: } 25 \\
M_{1}: 16\end{array}$ & RSBRT & $\mathrm{GTV}+\mathrm{I}-2 \mathrm{~mm}$ & $V_{93 \%}>97$ \\
\hline $\begin{array}{l}\text { Kim et al, } \\
2013^{15}\end{array}$ & Retrospective & $\begin{array}{l}\text { Not } \\
\text { surgical } \\
\text { candidates }\end{array}$ & $\begin{array}{l}26 \\
(16)\end{array}$ & $\begin{array}{l}\text { Stage } \\
\text { I-IV }\end{array}$ & $\begin{array}{l}\text { LINAC or RRS } \\
\text { or RSBRT }\end{array}$ & $\mathrm{GTV}+2 \mathrm{~mm}$ & $\begin{array}{l}\text { To } 80 \%-93 \% \\
\text { isodose }\end{array}$ \\
\hline $\begin{array}{l}\text { Comito } \\
\text { et al, } 2017^{16}\end{array}$ & Retrospective & $\begin{array}{l}\text { Isolated } \\
\text { Rec }\end{array}$ & $\begin{array}{l}31 \\
(20)\end{array}$ & $\begin{array}{l}\text { Local } \\
\text { Rec }\end{array}$ & $\begin{array}{l}\text { Rapidarc } \\
\text { FFF }\end{array}$ & $\begin{array}{l}\text { ITV }+5 \mathrm{~mm} \text { or } \\
\mathrm{GTV}+5-7 \mathrm{~mm}\end{array}$ & $\begin{array}{l}\text { To mean PTV } \\
\text { dose }\end{array}$ \\
\hline $\begin{array}{l}\text { Koong et al, } \\
2017^{17}\end{array}$ & Retrospective & $\begin{array}{l}\text { Previously } \\
\text { irradiated } \\
\text { local Rec }\end{array}$ & $\begin{array}{l}23 \\
(14)\end{array}$ & $\begin{array}{l}\text { Local } \\
\text { Rec, } M_{0}\end{array}$ & $\begin{array}{l}\text { RSBRT or } \\
\text { standard LINAC }\end{array}$ & ITV $+2-3 \mathrm{~mm}$ & NR \\
\hline
\end{tabular}

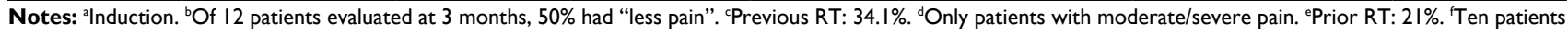
received SBRT as a boost after chemoradiation. ${ }^{8}$ Elevated aspartate/alanine aminotransferase: $10 \%$.

Abbreviations: 3D-CRT, 3D-conformal radiation therapy; CC, cranio-caudally; CR, complete response; CTCAE, Common Terminology Criteria for Adverse Events; CTC, Common Toxicity Criteria; CTV, clinical target volume; EORTC, European Organization for Research and Treatment of Cancer; EQD, biologically equivalent doses in 2 Gy fractions; FFF, filter flattering free; GI, gastrointestinal; GTV, gross tumor volume; ICRU, International Commission on Radiation Units; ITV, internal tumor volume; LA, locally advanced; LINAC, linear accelerator; M, metastases; NA, not administered; N, nodes; NR, not reported; NRS, Numerical Rating Scale; PR, partial response; PTV, planning target volume; RAA, reduction of analgesic administration; Rec, recurrence; RRS, robotic radiosurgery; RSBRT, stereotactic radiosurgery; RT, radiation therapy; RTOG, Radiation Therapy Oncology Group; SAA, suspension of analgesic administration; SBRT, stereotactic RT; SF, single fraction; VAS, visual analog scale; VMAT, volumetric modulated arc therapy; WHO, World Health Organization. 


\begin{tabular}{|c|c|c|c|c|c|c|}
\hline $\begin{array}{l}\text { RT dose, median } \\
\text { (range) }\end{array}$ & $\begin{array}{l}\text { EQD2 } \\
\alpha / \beta: 10 \\
\text { (median) }\end{array}$ & $\begin{array}{l}\text { EQD2 } \\
\alpha / \beta: 3 \\
\text { (median) }\end{array}$ & $\begin{array}{l}\text { \% of patients } \\
\text { receiving } \\
\text { chemotherapy }^{\mathrm{a}}\end{array}$ & $\begin{array}{l}\text { Pain response rate, \% } \\
\text { (criteria) }\end{array}$ & $\begin{array}{l}\text { Pain-free } \\
\text { survival } \\
\text { (months) }\end{array}$ & $\begin{array}{l}\text { Grade } 3-4 \text { toxicity \% } \\
\text { (scale) }\end{array}$ \\
\hline $\begin{array}{l}45 \text { Gy in three } \\
\text { fractions }\end{array}$ & 93.8 & 162.0 & NA & NR & $\begin{array}{l}\text { At } 2 \\
\text { weeks } \\
\text { increased } \\
\text { pain }(P \text { : } \\
0.008)^{\mathrm{b}}\end{array}$ & $\begin{array}{l}\text { Gastric-duodenal } \\
\text { mucositis/ulceration: } \\
\text { I8.0 } \\
\text { Gastric perforation: } 4.5 \\
\text { (WHO) }\end{array}$ \\
\hline $\begin{array}{l}40 \text { Gy in } 2 \text { Gy/fraction } \\
(3 D-C R T)+16.5 \text { Gy } \\
(14-17) \\
\text { SF RRS boost }\end{array}$ & 76.4 & 104.4 & $\begin{array}{l}70.0^{\mathrm{a}} \\
\text { ( } 6 \text { before RT; I5 } \\
\text { concurrent to } \\
\text { 3D-CRT) }\end{array}$ & $\begin{array}{l}\text { RAA: } 55.6 \\
\text { (NR) }\end{array}$ & $N R$ & $\begin{array}{l}\text { Acute: duodenal } \\
\text { obstruction } 3.3 \text {; late } 0.0 \\
\text { (RTOG) }\end{array}$ \\
\hline $\begin{array}{l}25.5 \text { Gy in three } \\
\text { fractions (15-30) }\end{array}$ & 39.3 & 58.6 & 100 after & $\begin{array}{l}\text { CR: } 48.4 \\
\text { PR: } 51.6^{\mathrm{d}} \\
(0-10 \text { scale })\end{array}$ & $\begin{array}{l}\text { I8-24 } \\
\text { weeks }\end{array}$ & $\begin{array}{l}\text { Acute: duodenitis (I4.I) } \\
\text { gastritis (I2.9) diarrhea } \\
\text { (3.5); late: hemorrhage/ } \\
\text { obstruction (8.2) } \\
\text { (CTC 2.0) }\end{array}$ \\
\hline $\begin{array}{l}45 \text { Gy }(32-55) \text { in four } \\
(3-6) \text { fractions }\end{array}$ & 79.7 & 128.2 & NA & $\begin{array}{l}\text { “Pain relief”: } 90.0 \\
\text { (VAS) }\end{array}$ & $N R$ & $\begin{array}{l}\text { Acute: } 0.0 \\
\text { Late: } 0.0 \\
\text { (RTOG) }\end{array}$ \\
\hline $\begin{array}{l}30 \text { Gy in three } \\
\text { fractions }\end{array}$ & 50.0 & 78.0 & $100^{\mathrm{a}}$ and after & $\begin{array}{l}\text { No significant reduction } \\
\text { (VAS) }\end{array}$ & $N R$ & $\begin{array}{l}\text { Acute: } 0.0 \\
\text { Late: } 0.0 \\
\text { (CTC 3.0) }\end{array}$ \\
\hline 24 Gy SF (I8-25) & 68.0 & 129.6 & $90^{\mathrm{a}}$ and/or after & $\begin{array}{l}\text { CR: } 81.3 \\
(N R)\end{array}$ & NR & $\begin{array}{l}\text { Acute GI: } 4.2 \\
\text { Late: } 0.0 \\
(\mathrm{NR})\end{array}$ \\
\hline $\begin{array}{l}25 \text { Gy in five fractions } \\
(20-35)\end{array}$ & 31.3 & 40.0 & $100^{a}$ & $\begin{array}{l}\text { CR: } 25.0 \\
\text { PR: } 31.3 \\
\text { RAA: } 40.0 \\
\text { (NR) }\end{array}$ & NR & $\begin{array}{l}\text { Acute: } 0.0 \\
\text { Late: duodenal bleeding: } \\
6.2 \\
\text { (RTOG) }\end{array}$ \\
\hline $\begin{array}{l}25 \text { Gy in five fractions } \\
(20-27)\end{array}$ & 31.3 & 40.0 & 28 after SBRT & $\begin{array}{l}57 \\
\text { "Effective palliation" } \\
(\mathrm{NR})\end{array}$ & $N R$ & $\begin{array}{l}\text { Acute: } 0.0 \\
\text { Late: small bowel } \\
\text { obstruction: } 6.0 \\
\text { (NR) }\end{array}$ \\
\hline $\begin{array}{l}45 \text { Gy in six fractions } \\
(36-45)\end{array}$ & 65.5 & 95.0 & $100^{\mathrm{a}}$ & $\begin{array}{l}\text { SAA: } 63.6 \\
\text { RAA } 36.4 \\
\text { (NRS) }\end{array}$ & $N R$ & $\begin{array}{l}\text { Acute: } 0.0 \\
\text { Late: } 0.0 \\
\text { (CTC } 3.0 \text { ) }\end{array}$ \\
\hline 33 Gy in five fractions & 45.7 & 63.4 & $\begin{array}{l}90^{\mathrm{a}} \\
100 \text { after }\end{array}$ & $\begin{array}{l}\text { Reduction of } 8 \text { points from } \\
\text { baseline: } 25 \text { points } \\
\text { (QLQ-PAN } 26 \text { ) }\end{array}$ & $N R$ & $\begin{array}{l}\text { Acute: duodenal ulcer: } \\
\text { 2.0s; late: duodenal } \\
\text { ulcer/bleeding: } 6.4 \\
\text { (NR) }\end{array}$ \\
\hline $\begin{array}{l}36 \text { Gy in three } \\
\text { fractions ( } 30-48 \text { in } \\
\text { three to four fractions) }\end{array}$ & 66.0 & 108.0 & $\begin{array}{l}8^{a} \\
8 \text { after }\end{array}$ & $\begin{array}{l}\text { SAA: } 50.0 \\
\text { RAA: } 15.0 \\
\text { (NRS) }\end{array}$ & $N R$ & $\begin{array}{l}\text { Acute: } 0.0 \\
\text { Late: } 0.0 \\
(\mathrm{NR})\end{array}$ \\
\hline $\begin{array}{l}24(24-36) \text { Gy in one } \\
\text { to three fractions }\end{array}$ & 68.0 & 135.0 & $\begin{array}{l}15.0^{\mathrm{a}} \\
23.0 \text { after }\end{array}$ & $\begin{array}{l}\text { Pain relief: } 75.0 \\
\text { SAA: } 31.3 \\
\text { (NR) }\end{array}$ & NR & $\begin{array}{l}\text { Acute: } 0.0 \\
\text { Late: } 0.0 \\
\text { (RTOG/EORTC) }\end{array}$ \\
\hline $45 \mathrm{~Gy}$ in six fractions & 65.5 & 95.0 & $\begin{array}{l}20^{\mathrm{a}} \\
77 \text { after }\end{array}$ & $\begin{array}{l}\text { SAA: } 58.0 \\
\text { RAA: } 40.0 \\
\text { (NRS) }\end{array}$ & NR & $\begin{array}{l}\text { Acute: } 0.0 \\
\text { Late: } 0.0 \\
\text { (CTCAE V.4.0) }\end{array}$ \\
\hline 25 Gy in five fractions & 31.3 & 40.0 & $26.1^{\mathrm{a}}$ & $\begin{array}{l}\text { "Relative improvement" } 57.1 \\
\text { (NR) }\end{array}$ & NR & $\begin{array}{l}\text { Acute: GI (8.7); late: } 0.0 \\
\text { (CTCAE v. } 4.0 \text { ) }\end{array}$ \\
\hline
\end{tabular}


Author, year

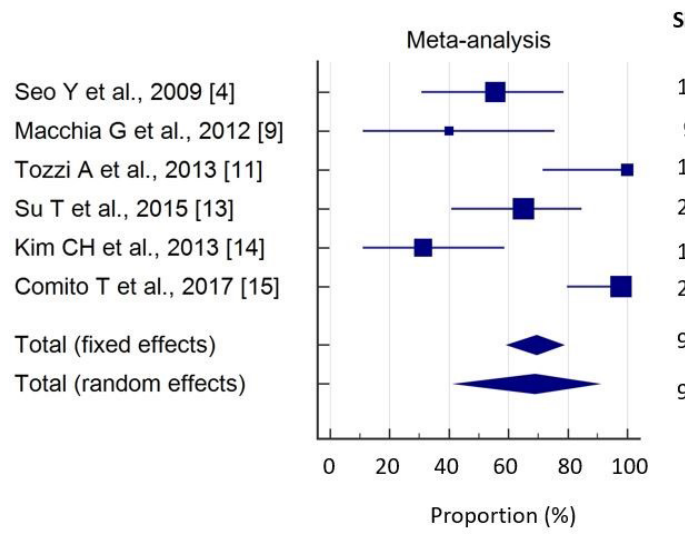

Sample Proportion

Size

(\%)

18.55

$5.55 \quad 30.75-78.47$

40.00

100.00

65.00

31.25

98.00

69.50

68.83

$11.05-75.45$

$71.50-100.00$

$40.78-84.60$

$11.01-58.66$

$79.72-100.00$

$59.49-78.31$

$42.44-89.90$

Heterogenity $Q(d f=5)=36.88 . p<0.0001 ; l^{2}=86.44 \%$

Figure 2 Overall response rate to analgesic administration in terms of reduction and suspension of analgesic therapy.

Notes: Based on six studies ( 94 patients), the overall response rate to analgesic administration in terms of reduction or suspension of analgesic therapy was $69.5 \%$ ( $95 \% \mathrm{Cl}$, $59.5 \%-78.3 \%)$, with high heterogeneity between studies ( $Q^{2}$ test: $P<0.000$ I; $\left.I^{2}=86.44 \%\right)$.

Abbreviation: $\mathrm{df}$, degrees of freedom.

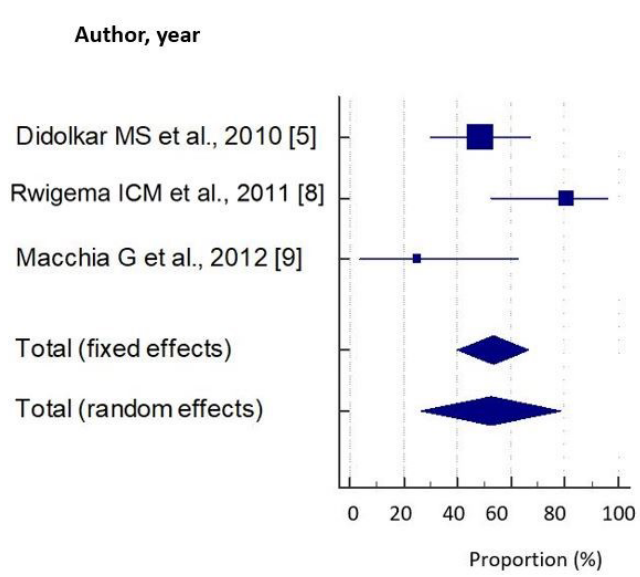

\begin{tabular}{|c|c|c|c|c|}
\hline Sample & Proportion & $95 \% \mathrm{Cl}$ & Wei & ht (\%) \\
\hline size & (\%) & & Fixed & Random \\
\hline 31 & 48.38 & $30.15-66.93$ & 54.24 & 37.75 \\
\hline 16 & 81.25 & $54.35-95.95$ & 28.81 & 33.53 \\
\hline 9 & 25.00 & $3.81-62.66$ & 16.95 & 28.73 \\
\hline 56 & 54.25 & $40.76-67.29$ & 100.00 & 100.00 \\
\hline 56 & 53.23 & $26.08-79.38$ & 100.00 & 100.00 \\
\hline
\end{tabular}

Figure 3 Overall complete response to pain

Notes: Based on three studies (56 patients), the overall complete response rate to pain was $54.2 \%(95 \% \mathrm{Cl}, 40.8 \%-67.3 \%)$, with high heterogeneity $\left(Q^{2}\right.$ test: $P<0.013$; $P=76.68 \%)$.

Abbreviation: $\mathrm{df}$, degrees of freedom.

Author, year

Didolkar MS et al., 2010
Shen Z et al., 2010 [6]
Macchia G et al., 2012 [9]
Kim CH et al., 2013 [14]
Koong AJ et al.,2017 [16]
Total (fixed effects)
Total (random effects)

Total (random effects)

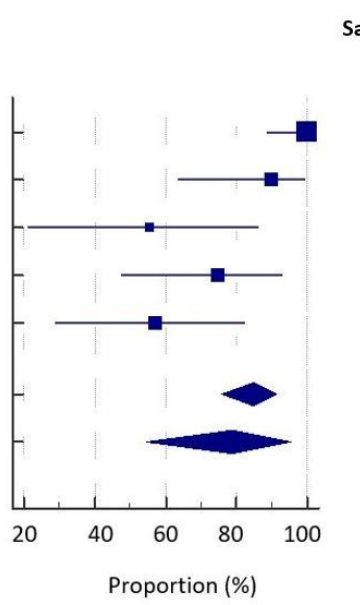

Sample

size

31

15

9

16

14

85

85

Heterogenity $Q(d f=4)=24.42 . p=0.001 ; l^{2}=86.63 \%$

Figure 4 Overall global response to pain.

Notes: Based on five studies (85 patients), the global response rate to pain in terms of complete and partial response rate was $84.9 \%$ ( $95 \% \mathrm{Cl}$, $75.8 \%-91.6 \%)$, with high heterogeneity ( $Q^{2}$ test: $P<0.001 ; l^{2}=83.63 \%$ ).

Abbreviation: $\mathrm{df}$, degrees of freedom. 
Brunner et al, ${ }^{18}$ but the different methods of analysis and the selection criteria should be considered. In fact, in our analysis, only studies reporting data on pain relief were included.

The efficacy of RT in pain relief in this setting is not new. Patients with LAPC treated with standard chemoradiation experienced pain reduction (in $35 \%-65 \%$ of cases).$^{20}$ However, the rate of toxicity recorded in SBRT series seems lower compared to standard radio-chemotherapy. In fact, rates of $36 \%-79 \%$ grade $3-4$ toxicity and $41 \%$ of grade $4-5$ toxicity were reported in concurrent chemoradiation studies. ${ }^{21-23}$ Furthermore, the survival outcome recorded in series of chemoradiation and SBRT seems relatively similar. ${ }^{24}$

Also, chemotherapy alone can reduce pain in patients with LAPC. ${ }^{25}$ Therefore, it could be interesting to compare the palliation results of chemotherapy with the ones of SBRT or to evaluate the efficacy in terms of pain relief by combining the two treatments. Unfortunately, our analysis is not able to provide indications on these topics because in most series, both SBRT and chemotherapy were administered, and therefore, we cannot compare the two treatments. Furthermore, it is difficult to evaluate the efficacy of combining the two treatments because pain response was evaluated comparing the intensity of this symptom before and after SBRT and not before and after the whole treatment (SBRT+chemotherapy).

Other ablative therapies have been proposed in the treatment of LAPC, such as radiofrequency ablation, irreversible electroporation, high-intensity focused ultrasound, iodine 125 , cryosurgery, photodynamic therapy, and microwave ablation. A literature review reported the possibility to reduce pain with some of these treatments such as radiofrequency ablation, irreversible electroporation, SBRT, and high-intensity focused ultrasound. However, among these treatments, SBRT was found to be the only procedure without related mortality and with proven efficacy in QoL improvement. ${ }^{26}$

Based on the results of this analysis, SBRT can be considered as an option in the treatment of symptomatic patients with LAPC. However, a high level of accuracy is required in treatment planning and delivery to reduce the risk of GI complications. Guidelines are available in literature to minimize the probability of side effects. ${ }^{18,19}$ Furthermore, more sophisticated and advanced techniques are now available to improve precision in SBRT delivery, such as intensitymodulated $\mathrm{RT},{ }^{27}$ simultaneous integrated boost, ${ }^{3,28}$ respiratory gating, ${ }^{29}$ and adaptive re-planning. ${ }^{30}$

In conclusion, SBRT achieves pain relief in most patients with PC. Furthermore, late toxicity was recorded in only a minority of studies and, even in these, with an incidence of
$<10 \%$. Therefore, the recorded toxicity can be considered acceptable. Further prospective studies on the palliative role of SBRT in LAPC are needed to define the optimal dose/fractionation and the best systemic therapies modality integration with the aim to reduce toxicity and improve the palliative outcome. Finally, QoL and, particularly, pain control should be considered as an endpoint in all future trials on this emerging treatment technique.

\section{Acknowledgment}

The abstract has previously been presented as a poster at the 36th Annual meeting of the European Society for Radiotherapy \& Oncology (ESTRO), Vienna, Austria, May 5-9, 2017 and at XXVII Congresso Nazionale AIRO (Associazione Italiana Radioterapia Oncologia), Rimini, Italy, November 11-13, 2017 as an oral communication.

\section{Disclosure}

The authors report no conflicts of interest in this work.

\section{References}

1. Amini A, Jones BL, Stumpf P, et al. Patterns of care for locally advanced pancreatic adenocarcinoma using the National Cancer Database. Pancreas. 2017;46(7):904-912.

2. Huguet F, Mukherjee S, Javle M. Locally advanced pancreatic cancer: the role of definitive chemoradiotherapy. Clin Oncol (R Coll Radiol). 2014;26(9):560-568.

3. Buwenge M, Cilla S, Guido A, et al. Individually optimized stereotactic radiotherapy for pancreatic head tumors: a planning feasibility study. Rep Pract Oncol Radiother. 2016;21(6):548-554.

4. Hoyer M, Roed H, Sengelov L, et al. Phase-II study on stereotactic radiotherapy of locally advanced pancreatic carcinoma. Radiother Oncol. 2005;76(1):48-53.

5. Seo Y, Kim MS, Yoo S, et al. Stereotactic body radiation therapy boost in locally advanced pancreatic cancer. Int J Radiat Oncol Biol Phys. 2009;75(5):1456-1461.

6. Didolkar MS, Coleman CW, Brenner MJ, et al. Image-guided stereotactic radiosurgery for locally advanced pancreatic adenocarcinoma results of first 85 patients. $J$ Gastrointest Surg. 2010;14(10):1547-1559.

7. Shen ZT, Wu XH, Li B, Wang L, Zhu XX. Preliminary efficacy of CyberKnife radiosurgery for locally advanced pancreatic cancer. Chin J Cancer. 2010;29(9):802-809.

8. Polistina F, Costantin G, Casamassima F, et al. Unresectable locally advanced pancreatic cancer: a multimodal treatment using neoadjuvant chemoradiotherapy (gemcitabine plus stereotactic radiosurgery) and subsequent surgical exploration. Ann Surg Oncol. 2010;17(8):2092-2101.

9. Rwigema JC, Parikh SD, Heron DE, et al. Stereotactic body radiotherapy in the treatment of advanced adenocarcinoma of the pancreas. Am J Clin Oncol. 2011;34(1):63-69.

10. Macchia G, Morganti AG, Cilla S, et al. Quality of life and toxicity of stereotactic radiotherapy in pancreatic tumors: a case series. Cancer Invest. 2012;30(2):149-155.

11. Wild AT, Hiniker SM, Chang DT, et al. Re-irradiation with stereotactic body radiation therapy as a novel treatment option for isolated local recurrence of pancreatic cancer after multimodality therapy: experience from two institutions. J Gastrointest Oncol. 2013;4(4):343-351. 
12. Tozzi A, Comito T, Alongi F, et al. SBRT in unresectable advanced pancreatic cancer: preliminary results of a mono-institutional experience. Radiat Oncol. 2013;8:148.

13. Herman JM, Chang DT, Goodman KA, et al. Phase 2 multi-institutional trial evaluating gemcitabine and stereotactic body radiotherapy for patients with locally advanced unresectable pancreatic adenocarcinoma. Cancer. 2015;121(7):1128-1137.

14. Su TS, Liang P, Lu HZ, et al. Stereotactic body radiotherapy using CyberKnife for locally advanced unresectable and metastatic pancreatic cancer. World J Gastroenterol. 2015;21(26):8156-8162.

15. Kim CH, Ling DC, Wegner RE, et al. Stereotactic body radiotherapy in the treatment of pancreatic adenocarcinoma in elderly patients. Radiat Oncol. 2013;8:240.

16. Comito T, Cozzi L, Zerbi A, et al. Clinical results of stereotactic body radiotherapy (SBRT) in the treatment of isolated local recurrence of pancreatic cancer after R0 surgery: a retrospective study. Eur J Surg Oncol. 2017;43(4):735-742.

17. Koong AJ, Toesca DAS, von Eyben R, Pollom EL, Chang DT. Re-irradiation with stereotactic body radiation therapy after prior conventional fractionation radiation for locally recurrent pancreatic adenocarcinoma. Adv Radiat Oncol. 2017;18:27-36.

18. Brunner TB, Nestle U, Grosu AL, Partridge M. SBRT in pancreatic cancer: what is the therapeutic window? Radiother Oncol. 2015;114(1):109-116.

19. Murphy JD, Christman-Skieller C, Kim J, Dieterich S, Chang DT, Koong AC. A dosimetric model of duodenal toxicity after stereotactic body radiotherapy for pancreatic cancer. Int J Radiat Oncol Biol Phys. 2010;78(5):1420-1426.

20. Palta M, Willett CG, Czito BG. Pancreatic cancer. In: Halperin EC, Walter DE, Perez CA, Brady LW, editors. Principles and Practice of Radiation Oncology. 6th ed. Philadelphia PA: Wolters Kulwer-Lippincott William and Wilkins; 2013:1189-1202.

21. Chauffert B, Mornex F, Bonnetain F, et al. Phase III trial comparing intensive induction chemoradiotherapy (60 Gy, infusional 5-FU and intermittent cisplatin) followed by maintenance gemcitabine with gemcitabine alone for locally advanced unresectable pancreatic cancer. Definitive results of the 2000-01 FFCD/SFRO study. Ann Oncol. 2008;19(9):1592-1599.

22. Loehrer PJ, Feng Y, Cardenes H, et al. Gemcitabine alone versus gemcitabine plus radiotherapy in patients with locally advanced pancreatic cancer: an Eastern Cooperative Oncology Group trial. J Clin Oncol. 2011;29(31):4105-4112.

23. Morganti AG, Valentini V, Macchia G, et al. 5-Fluorouracil-based chemoradiation in unresectable pancreatic carcinoma: Phase I-II doseescalation study. Int J Radiat Oncol Biol Phys. 2004;59(5):1454-1460.

24. Buwenge M, Cellini F, Silvestris N, et al. Robotic radiosurgery in pancreatic cancer: a systematic review. World J Gastroenterol. 2015;21(31):9420-9429.

25. Bernhard J, Dietrich D, Glimelius B, Bodoky G, Scheithauer W, Herrmann R. Clinical benefit response in pancreatic cancer trials revisited. Oncol Res Treat. 2014;37(1-2):1-48.

26. Rombouts SJ, Vogel JA, van Santvoort HC, et al. Systematic review of innovative ablative therapies for the treatment of locally advanced pancreatic cancer. Br J Surg. 2015;102(3):182-193.

27. Kumar R, Wild AT, Ziegler MA, et al. Stereotactic body radiation therapy planning with duodenal sparing using volumetric-modulated arc therapy vs intensity-modulated radiation therapy in locally advanced pancreatic cancer: a dosimetric analysis. Med Dosim. 2013;38(3):243-250.

28. Yang W, Reznik R, Fraass BA, et al. Dosimetric evaluation of simultaneous integrated boost during stereotactic body radiation therapy for pancreatic cancer. Med Dosim. 2015;40(1):47-52.

29. Taniguchi CM, Murphy JD, Eclov N, et al. Dosimetric analysis of organs at risk during expiratory gating in stereotactic body radiation therapy for pancreatic cancer. Int J Radiat Oncol Biol Phys. 2013;85(4): 1090-1095.

30. Li Y, Hoisak JD, Li N, et al. Dosimetric benefit of adaptive re-planning in pancreatic cancer stereotactic body radiotherapy. Med Dosim. $2015 ; 40(4): 318-324$
Journal of Pain Research

\section{Publish your work in this journal}

The Journal of Pain Research is an international, peer reviewed, open access, online journal that welcomes laboratory and clinical findings in the fields of pain research and the prevention and management of pain. Original research, reviews, symposium reports, hypothesis formation and commentaries are all considered for publication.

\section{Dovepress}

The manuscript management system is completely online and includes a very quick and fair peer-review system, which is all easy to use. Visit http://www.dovepress.com/testimonials.php to read real quotes from published authors. 